\title{
Modeling Business Process Knowledge Using a Combined DEMATEL Approach and Fuzzy Network Analysis Process
}

\author{
Elham Taghizadeh ${ }^{1} \&$ Elaheh Taghizadeh ${ }^{2}$ \\ ${ }^{1}$ School of Industrial Engineering, Wayne State University, Detroit, USA \\ ${ }^{2}$ Quality Assurance and Process Analyst, Saman Electronic Payment (SEP), Tehran, Iran \\ Correspondence: Elham Taghizadeh, School of Industrial Engineering, Wayne State University, Detroit, MI 48202, \\ USA. Tel: 1-313-686-3929. E-mail: Elham.taghizadeh@wayne.edu
}

Received: May 27, 2021

doi:10.5430/jms.v12n2p7
Accepted: June 25, 2021

Online Published: July 6, 2021

URL: https://doi.org/10.5430/jms.v12n2p7

\begin{abstract}
One of the most valuable assets of an organization in today's competitive world is knowledge resources because they can create value. Knowledge management aims to identify and manage the organization; part of the valuable organizational knowledge is related to business processes. In this study, a framework for identifying and modeling processes is presented. Different dimensions of knowledge affect business processes and ultimately affect the value of the organization. To investigate and confirm the dimensions of knowledge, a process of fuzzy network analysis and integration of Demeter multi-criteria decision-making methods has been used to find cause-and-effect relationships and prioritize the dimensions and examples of knowledge. First, the key and valuable processes of the organization is identified during the map and then a model including the dimensions of knowledge such as knowledge input to the process, knowledge of the environment outside the process, knowledge during the process, Knowledge of the process output and Knowledge about the process has been developed. Next, dimensions, knowledge related to each dimension were presented. After analyzing the matrix, it was observed that Knowledge from the outside environment, knowledge about the process, and Knowledge during the process have the most significant impact on the organization's value, respectively.
\end{abstract}

Keywords: knowledge evaluation, organization value, business process knowledge, knowledge identification, DEMATEL, fuzzy network analysis process

\section{Introduction}

Today, to gain a sustainable competitive advantage, most dynamic organizations in organizational process management have turned their attention from organizational process automation to process-related knowledge. Therefore, identifying and modeling knowledge is essential to improve processes or reduce errors (Mirshahi 2014). In this article, a model is presented to identify and prioritize business process knowledge dimensions comprehensively. For this purpose, the Iran Kish Credit Card Company has been selected for the study. Research on knowledge management has dealt chiefly with the organization's knowledge management processes, but the research that deals only with the knowledge of business processes is minimal, although it is essential. In similar studies, only the basic model of process knowledge classification is briefly presented. This study aims to identify and model the critical processes of the organization and related knowledge resources. Of course, in the end, knowledge resources and processes are ranked based on their effect on the organization's value.

The first step, such as business process architecture, examines process models to show the main processes and their correct classification. Porter's value chain model was used to show the key processes and their flow to create value for the organization. The APQC framework was also selected as a standard classification to classify processes from level zero to sub-process. After identifying the key processes and classifying them, a process map was drawn. A combination of Porter's value chain (as level zero model) and APQC (level one only) was used to draw this map. To identify and evaluate process knowledge, according to previous studies, we first extracted the dimensions and examples of business process knowledge. With the opinion of experts, the models and dimensions were approved, and then in the last stage, according to the multi-criteria decision-making method, the dimensions were ranked based on their effect, on the value of the organization, the degree of importance. Finally, the DEMATEL method was used to show the flow of their cause and effect, and the prioritization of these dimensions was done using the fuzzy 
network analysis process method (Ayoubi 2011, Alavi 2001).

\subsection{Statement of the Problem}

Due to the importance of the two issues of processes and knowledge in leading organizations and given the value that these two assets have for the organization, much research has been done in the present decade on both issues. However, in these studies, little work has been done examining and identifying the knowledge of business processes, especially in the dimensions that create the most value for the organization. Identifying and modeling this valuable knowledge, good planning, and investment can create differentiation, competitive advantage, and customer satisfaction in the organization.

Knowledge is considered an integral part of organizational processes and cannot be managed separately. In principle, it can be said that this knowledge is included in all types of organizational processes. One of the advantages of process knowledge modeling is identifying knowledge resources to provide value-added goods and services, reducing mistakes, and reworking by relying on organizational experiences, saving problem-solving time, and increasing innovation and creativity (Roblek, Vasja, et al. 2013, Qureshi 2012). Furthermore, identifying and evaluating knowledge processes can result in finding the primary sources of knowledge creation and opportunity learning, improving customer responsiveness, decision-making, and problem-solving through access to knowledge and internal and external specialists, evaluating intangible assets and competitive advantage, and finding valuable knowledge in the organization. Finally, the objectives of this study include the following:

1. Determining the dimensions and examples of business process knowledge.

2. Provide a business process knowledge model.

3. Creating a framework for evaluating the effect of business process knowledge dimensions on organizational value.

\section{Research Background}

\subsection{Theoretical Foundations}

Combining the two topics of knowledge management and process management leads to many mutual benefits in the organization's performance. Business process management methodology supports the knowledge management process. Gives an appropriate view of identifying existing risks and opportunities for future analysis as well as organizational processes based on instructions, rules, and workflows and other examples of knowledge in them, as well as the possibility of internalizing knowledge by identifying changes, bottlenecks and defining the critical points of the process (Bloodgood, J. M., \& Salisbury, W. D. 2001). Business processes are the key to the success of any organization. Therefore, having a reliable business process management method in organizations is essential, and organizations have learned that business process management is a substantial investment in the rapid response to changes in the competitive environment. Business process management with multiple models required by organizations provides a unified and systematic way to design, implement, and manage organizations' business processes. Individuals and systems are involved in each process. (Qasemian, J., \& Jafarzadeh Kermani, Z, 2019).

In literature, process-related knowledge can be explicitly acquired and embedded within itself. Like the knowledge extracted, we could model this knowledge within the framework of instructions, flowcharts, and rules. This knowledge is usually built to support decision-making processes that can be demonstrated through a series of rules. A portion of evident process knowledge can be recorded by an interface (such as log files in a process management system).

On the other hand, knowledge is a process that cannot be represented by any intermediary, which is called tacit knowledge. Tacit knowledge is more hidden in the minds of employees of the organization. Like the experiences that employees gain over the years working with the process, this knowledge disappears as employees leave the organization. Therefore, knowledge of a dispersed process must be extracted in the minds of employees. This knowledge obtained after modeling should be available to the organization's people so that it can be used to benefit from standard work processes and improve these processes (Angeles, J. O, 2015).

Process knowledge is not as readily available as explicit knowledge and is not as inaccessible as tacit knowledge but is accessible by managing knowledge embedded in business processes or managing knowledge processes. Therefore, tangible resources create added value when combined with tacit knowledge. Furthermore, because of the difficulty of identifying and modeling knowledge embedded in processes, if the organization incorporates process knowledge identification and management into its programs, it has a competitive advantage over competitors (Entezari, Hassan, 1988).

The $\mathrm{z}$ value is to create the conditions for more significant benefits than the cost and success of an enterprise in the 
long run, which means that managers create value for all customers, shareholders, vendors, employees, and society broadest sense. In this case, any of the stakeholders who find that the organization does not gain value leaves the organization and endangers the organization's success. The company's value chain allows managers to gain insight into company processes. The value chain starts with the main components of product production or service delivery of institutions and includes processes performed to satisfy customers (Starkey, 2010).

\subsection{Previous Studies}

Previous research focused only on the organization's knowledge, but floating knowledge embedded in the primary processes has explicitly been considered in the present study. This category has been developed according to the factors that can affect the level of process knowledge.

Given the limitations of articles related to identifying and evaluating process knowledge and the value of institutional, organizational knowledge, the knowledge accumulated in processes can be essential in connecting these two concepts. To model and classify organizational processes, we used Marlon Dumas' book, in which he presented models such as Porter value chain, apps, and the ISO standard process map as basic models for classifying and displaying critical organizational processes (Dumas, 2013). Also, according to Miskins's article, an integrated method for identifying and modeling the optimal processes of the organization has been presented, the result of which has been used in organizational architecture planning. (Miskon.s, 2015) Also Table 1 refers to the background of research in modeling the dimensions of process knowledge, and in Table 2, the types of knowledge according to previous studies are presented to classify the dimensions of knowledge.

Table 1. Research background in the field of process knowledge modeling

\begin{tabular}{|c|c|c|c|}
\hline Row & Research title & Author & Research results \\
\hline 1 & $\begin{array}{l}\text { The conceptual } \\
\text { structure of business } \\
\text { process knowledge }\end{array}$ & (Angeles, J. O, 2015) & $\begin{array}{l}\text { The purpose of this study is to provide a structure to demonstrate } \\
\text { knowledge of business processes. Therefore, a model was } \\
\text { presented in which process knowledge includes four dimensions of } \\
\text { input knowledge, resource knowledge, knowledge of process } \\
\text { components, and finally, output knowledge. }\end{array}$ \\
\hline 2 & $\begin{array}{l}\text { Business Process } \\
\text { Knowledge } \\
\text { Framework }\end{array}$ & $\begin{array}{l}\text { (Dang, Jiangbo, et } \\
\text { al., 2008) }\end{array}$ & $\begin{array}{l}\text { This research introduces the knowledge of organizational processes } \\
\text { as an efficient solution that consists of three dimensions. Process } \\
\text { stakeholder perspectives, types of knowledge available, and } \\
\text { process knowledge goals. This study shows how business process } \\
\text { knowledge influences process design and stakeholder } \\
\text { communication. }\end{array}$ \\
\hline 3 & $\begin{array}{l}\text { Elements of } \\
\text { knowledge } \\
\text { management in } \\
\text { improving } \\
\text { organizational } \\
\text { processes }\end{array}$ & $\begin{array}{l}\text { (García-Holgado, } \\
\text { Alicia, et al , 2015) }\end{array}$ & $\begin{array}{l}\text { In this article, he pointed out that it is essential to pay attention to } \\
\text { process knowledge to improve processes; it has divided the various } \\
\text { dimensions of process knowledge during the process into several } \\
\text { categories in a table. Knowledge of the process (inputs), knowledge } \\
\text { of the process (Knowledge of individuals) knowledge of the } \\
\text { process (organizational learning). }\end{array}$ \\
\hline 4 & $\begin{array}{l}\text { Application of process } \\
\text { map in improving } \\
\text { business processes }\end{array}$ & (Mentzas, 2001) & $\begin{array}{l}\text { In a part of this article, in order to draw a process map, the } \\
\text { knowledge of the organization's processes is mentioned, and in the } \\
\text { presented model, three divisions for process knowledge, including } \\
\text { knowledge about the process, knowledge during the process, and } \\
\text { knowledge of the output of the process are mentioned. }\end{array}$ \\
\hline 5 & $\begin{array}{l}\text { Forecasting and } \\
\text { modeling the } \\
\text { dynamics of } \\
\text { organizational } \\
\text { knowledge }\end{array}$ & $\begin{array}{l}\text { (Nonaka, I., \& Von } \\
\text { Krogh, G, 2009) }\end{array}$ & $\begin{array}{l}\text { In this paper, dynamic modeling to identify the factors that cause } \\
\text { the loss of organizational knowledge of processes is based on the } \\
\text { model of Nonaka Takeuchi and scenarios that show how key } \\
\text { variables affect all stakeholders, including customers and suppliers. }\end{array}$ \\
\hline
\end{tabular}


Table 2. Background of the organization's knowledge

\begin{tabular}{ccc}
\hline Row & Example for Knowledge & References \\
\hline 1 & Stakeholder knowledge & (Shim, J. P. 1989) - (Nonaka, I., \& Von Krogh, G, 2009) - \\
& (Mashhadi 2020) \\
2 & Knowledge of competitors & (Taghizadeh E 2013) (Rabiee 2011) \\
& (Nonaka, I., \& Von Krogh, G, 2009) \\
3 & Market knowledge & (Dang, Jiangbo, et al. 2008) (Rabiee 2011) \\
4 & Legal requirements & (Dang, Jiangbo, et al. 2008) (Rabiee 2011) \\
5 & Forms, checklists & (Nonaka, 1994) (Noohpishe, N 2019) (McIver. 2016) (Rabiee \\
& 2011) - (Dang, Jiangbo, et al. 2008) \\
6 & Knowledge Documentation & (Entezari, 1988) - (Rabiee 2011) \\
7 & Systematic knowledge & (Nonaka, 1994) (Ouali, Sonya, 2016) (McIver. 2016) (Duran, D. E. \\
8 & Experience and skills & Suiles, J. J., 2017) \\
& (Nonaka, 1994) - (Nonaka, I., \& Von Krogh, G, 2009)- \\
9 & Technical knowledge & (Lee, Y. C 2011) \\
11 & & (Ouali, Sonya 2016) (McIver. 2016) \\
12 & Organizational experience & (Nonaka, I., \& Von Krogh, G, 2009) \\
& Mental model & (Nonaka 1994) (Mashhadi 2020) \\
& (Shim, J. P. 1989) (Entezari 1385) (Dang, Jiangbo 2008)
\end{tabular}

\section{Conceptual Model}

\subsection{Process Map}

Studies show no comprehensive standard or model for classifying and grouping processes from a managerial perspective. Some formal organizations have each made a specific classification based on their experiences, studies, and tastes. In this study, we have tried to make use of best practices Standards. Like organizational process architecture projects, after classifying and modeling organizational processes, we used sub-processes and main processes concerning two models, Porter, and APQC. Finally, to show the organization's critical processes and how they relate, we used the process map provided in ISO 9001. This process map is localized with the characteristics of the company's processes and results from library studies and interviews with company experts and the application of their points of view.

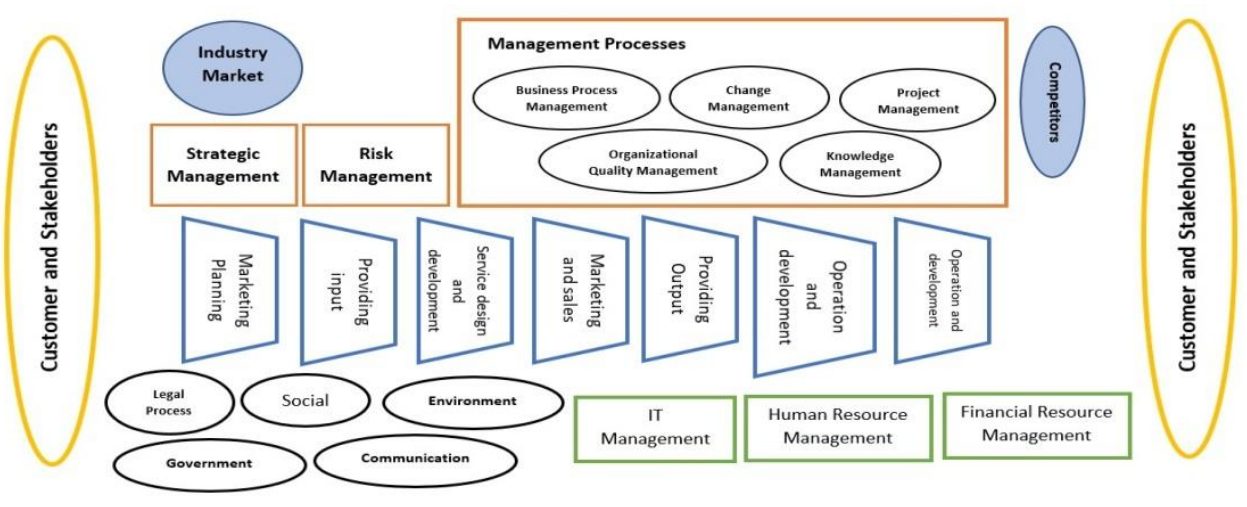

Figure 1. Company process map 


\subsection{Proposed Model of Process Knowledge Dimensions}

Considering previous studies on the dimensions of process knowledge and an overview based on the Saypoc model, we presented the following model, which shows all the process knowledge dimensions and their type of flow.

Knowledge input to the process: These are the things needed to start the process, and with the help of it, the work begins. Includes information, knowledge gained from organizational systems, databases, and strategic management knowledge. Knowledge during the process: It is created during the process by the people involved in the process. It includes the technical, knowledge, experience, and mental model of the main person in the person's decision points and creativity. Process output knowledge: Eventually leaves the process as knowledge and may enter the following process as knowledge. Includes output information, knowledge storage in organizational systems, and organizational experience. Knowledge outside the organization: any knowledge of the beneficiary's market and competitors or the process is practical and can be used. As well as the legal requirements are also in this category. Knowledge about process knowledge within the organization, but out of the process and change management process, knowledge management, process management, and quality management can affect and improve it.

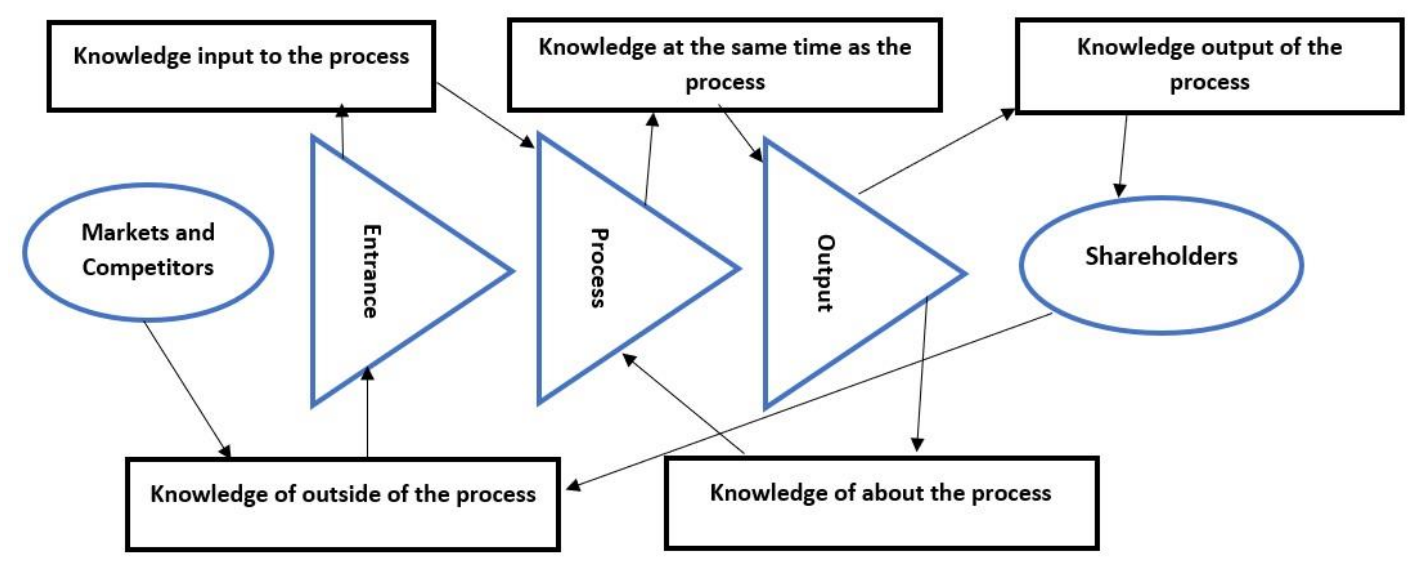

Figure 2. Model of business process knowledge dimensions

\section{Research Method}

This research is applied in terms of purpose, descriptive, and survey research regarding problem-solving and library and field methods in terms of data collection. The data collection tools are semi-structured interviews and a pairwise comparison questionnaire at the five options. To assess validity, respondents were asked to comment on the appropriateness of the questions for measuring the index, and their corrective comments were applied. The statistical population consists of experts and people involved in the organization's processes at the company level. Because the number of these people was limited, a pairwise comparison questionnaire was distributed among 15 experts.

Triangular fuzzy numbers are widely used due to easy calculations; therefore, fuzzy triangular numbers have been used in this research. Therefore, the implementation of decisions is definite. Therefore, by applying a series of actions, resulting in a fuzzy, it became definitive. The method used in this study to convert a fuzzy number ( $\mathrm{A}=$ $(\mathrm{l}, \mathrm{m}, \mathrm{u}))$ to a definite number (Yager center of gravity method) is as follows (Lee and Lin, 2011):

$$
d_{i j}=\frac{\left[\left(u_{i j}-l_{i j}\right)+\left(m_{i j}-l_{i j}\right)\right]}{3}+l_{i j}
$$

$$
i, j=1, \ldots, n
$$

DEMTAL method is widely used in decision making with multiple criteria, it is the creation of interrelationships between elements because Dematel will provide more valuable and accurate information about the internal relationships of criteria than other tools, this tool in this study to examine the relationship Internal has been used (Wu, 2008). 
Thomas L. Saati developed the network analysis process. In this hierarchical structure, the highest goal point is the problem, and the intermediate levels include the factors representing the higher level. Finally, the last level includes activities that need to be considered to achieve the goal (Jassbi, 2011). This technique is used to rank the dimensions and affirmation the value of the organization.

\section{Data Analysis}

First, the accuracy of the findings was confirmed by experts to check the validity of the research, then the importance of each dimension in the research model was examined through re-interviews with experts.

\subsection{Calculation of Internal Relations by Fuzzy DEMATEL Method}

At this stage, the internal relations of the main criteria of the problem, which are the exact dimensions of knowledge, are examined. To obtain these relationships, the fuzzy DEMATEL technique was used. In the first step, the criteria's importance and impact were determined using the defined scales with expert opinions. Then, the standard direct communication matrix after fuzzy was obtained according to Table 3:

Table 3. Normalized matrix of experts' opinions on the dimensions of knowledge

\begin{tabular}{|c|c|c|c|c|c|}
\hline & CR1 & CR2 & CR3 & CR4 & CR5 \\
\hline CR1 & $(0,0 ، 0)$ & $(0.15,0.19 ، 0.22)$ & $(0.22,0.25,0.28)$ & $(0.05,0.07,0.08)$ & $(0.12,0.16,0.2)$ \\
\hline $\mathrm{CR} 2$ & $(0.07,0.10,0.13)$ & $(0,0 \cdot 0)$ & $(0.07,0.10,0.13)$ & $(0.05,0.05,0.06)$ & $(0.18,0.22,0.26)$ \\
\hline CR3 & $(0.17,0.21,0.25)$ & $(0.12,0.16,0.20)$ & $(0,0 ، 0)$ & $(0.07 \cdot 0.08,0.10)$ & $(0.11,0.15,0.18)$ \\
\hline CR4 & $(0.09,0.13,0.17)$ & $(0.17,0.21,0.25)$ & $(0.28,0.32,0.32)$ & $(0,0 ، 0)$ & $(0.18,0.22,0.26)$ \\
\hline CR5 & $(0.08,0.12,0.15)$ & $(0.15,0.19,0.23)$ & $(0.08,0.12,0.15)$ & $(0.08,0.10 ، 0.12)$ & $(0,0 \bullet 0)$ \\
\hline
\end{tabular}

To calculate the complete communication matrix, de-fuzzing was performed, and definite values in the direct communication matrix were presented in Table 4. Based on the Dematel method results, we separated the criteria in terms of effectiveness or impressionability. Figure 3 shows the relationships and intrinsic importance of the dimensions of knowledge according to the results.

Table 4. The importance of the impact of knowledge dimensions

\begin{tabular}{cccccc}
\hline Criterion & $\mathrm{D}$ & $\mathrm{R}$ & $\mathrm{D}+\mathrm{R}$ & $\mathrm{D}-\mathrm{R}$ & effect \\
\hline Knowledge about & 1.828 & 1.621 & 3.449 & 0.567 & effective \\
Knowledge during & 1.355 & 2.055 & 3.41 & -0.7 & Impressionable \\
Input knowledge & 1.686 & 1.989 & 3.675 & -0.303 & Impressionable \\
$\begin{array}{c}\text { Knowledge from the } \\
\text { outside environment }\end{array}$ & 2.312 & 0.945 & 3.257 & 1.367 & effective \\
Output knowledge & 1.498 & 2.069 & 3.567 & -0.571 & Impressionable \\
\hline
\end{tabular}

As shown, the CR4 variable of extra-process knowledge has the most significant impact on other dimensions, and the CR1 variable, process knowledge, affects each dimension of process knowledge and is itself affected by the knowledge output from the process. Cause and effect relationships can be observed according to the direction of the arrows in the figure, proving the flow of the proposed process knowledge model. The other three variables are affected by the input from the output of the previous process takes effect. 


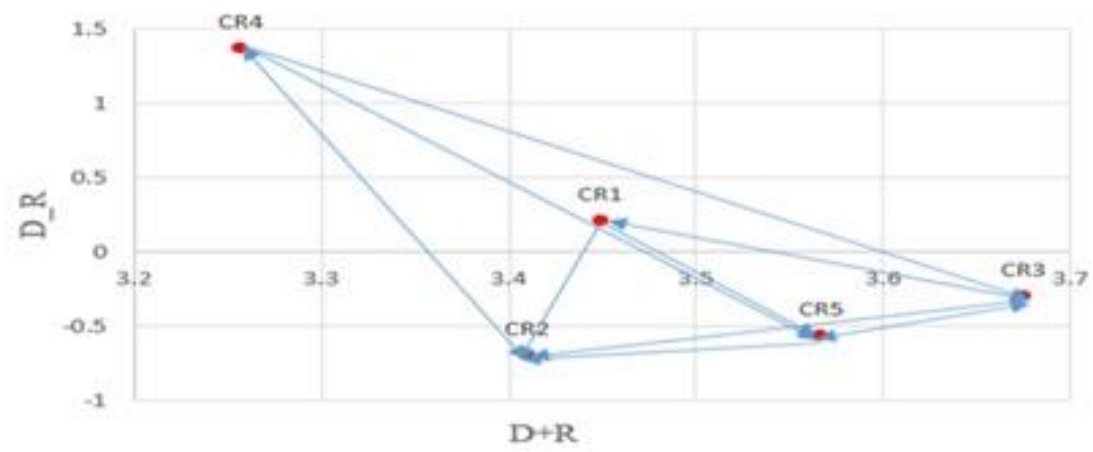

Figure 3. Relationships and internal importance of knowledge dimensions

\subsection{Priority Aspects of the Model With the Help of Network Analysis Techniques}

First, the experts' views were collected in 5 hours, and the matrix of pairwise comparisons was collected and then fuzzy. Then, geometric mean has been used to aggregate the views of experts in the network analysis method. In the fuzzy ANP method results, we are faced with pairwise comparison matrices to form weights or priority vectors that determine the importance of each dimension of knowledge to the goal and the importance of each instance of knowledge to the appropriate knowledge dimension. After the consensus of the experts and after ensuring that the experts' opinions are consistent in the next step, the weight of each instance is calculated about each dimension of knowledge related to it. In general, it can be said that the acceptable degree of incompatibility of a system depends on the decision-maker; But Bloodgood (2001) presents the number 0.1 as an acceptable limit and believes that if the inconsistency rate is more than 0.1 , it is better to reconsider the conclusions. Table 5 shows the matrix of pairwise comparisons.

Table 5. Matrix of pairwise comparisons of knowledge dimensions about the purpose and weight of each of them

\begin{tabular}{ccccccc}
\hline & CR1 & CR2 & CR3 & CR4 & CR5 & Weight \\
\hline CR1 & 1 & 3 & 3.8485 & 0.4665 & 3.8485 & 0.297 \\
CR2 & 0.4655 & 1 & 1.675 & 0.219 & 1.675 & 0.176 \\
CR3 & 0.3155 & 0.65025 & 1 & 0.1805 & 2 & 0.056 \\
CR4 & 3 & 5 & 5.9105 & 1 & 5.9105 & 0.411 \\
CR5 & 0.1805 & 0.3155 & 2 & 0.41925 & 1 & 0.056
\end{tabular}

\section{$\mathrm{CR}=\mathbf{0 . 0 0 7}<0.1$}

In the next step, to prioritize the dimensions and examples of knowledge, we need to consider the effects of factors on each other. For this purpose, the giant matrix is defined as follows: The formation of an unbalanced supermatrix, the calculation of a balanced matrix, and the calculation of a finite supermatrix using Super Decisions software and the results obtained from the T matrix the fuzzy dimethyl method have been used. This matrix was then normalized as the T matrix concerning the sum of the column values.

This is a large matrix that determines the effect of knowledge dimensions on instances of knowledge and shows the internal relationships of knowledge dimensions. Also, the T matrix obtained from the DEMATEL method has been used for internal relations of knowledge dimensions. The large non-T matrix must be converted to a significant $\mathrm{T}$ matrix using the normalization method. As a result, the sum of the values in each column of the large matrix will be one. Figure 4 shows the final weight of the dimensions. 
The final weight of the dimensions of knowledge

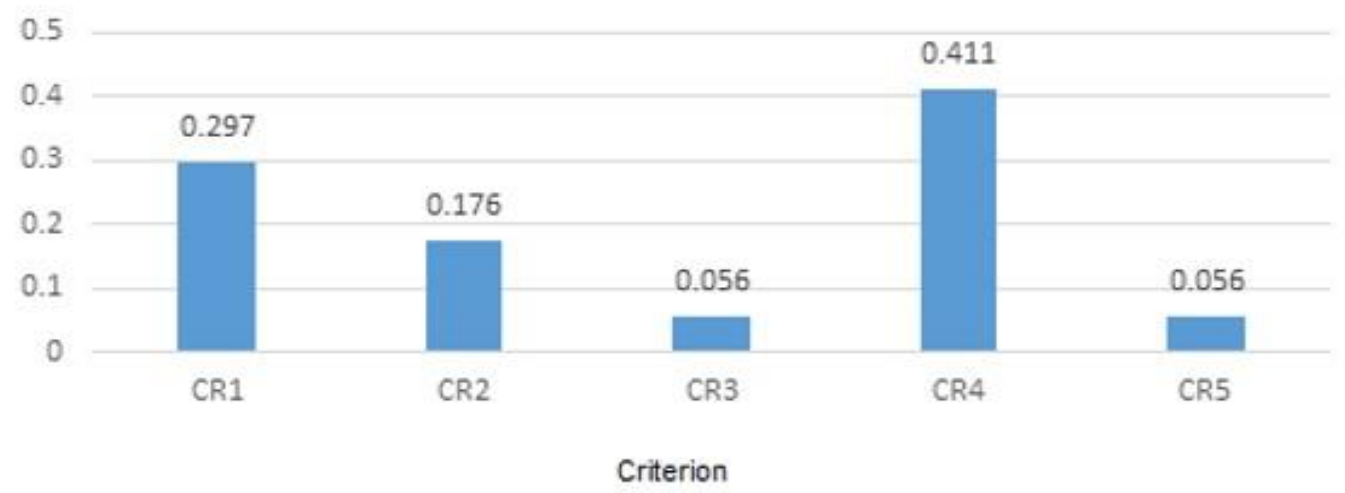

Figure 4. Graph of the final weight of the criteria by purpose

Dimension priority Based on the analysis results, it was determined that the most critical dimension of knowledge is knowledge from the outside environment with a weight of 0.411 . Then there is the process knowledge with a weight of 0.297 and the in-process knowledge with a weight of 0.176. Finally, process input knowledge and process output knowledge with the same weight are in fourth place.

To determine the importance and prioritization of each dimension of local weight knowledge, we calculated them; the results of their prioritization are shown in Figure 5. It ranks first among the examples of knowledge of stakeholders with a weight of 0.196 . The second to fifth ranks were competitors and top companies, process management knowledge, quality management knowledge, and market knowledge.

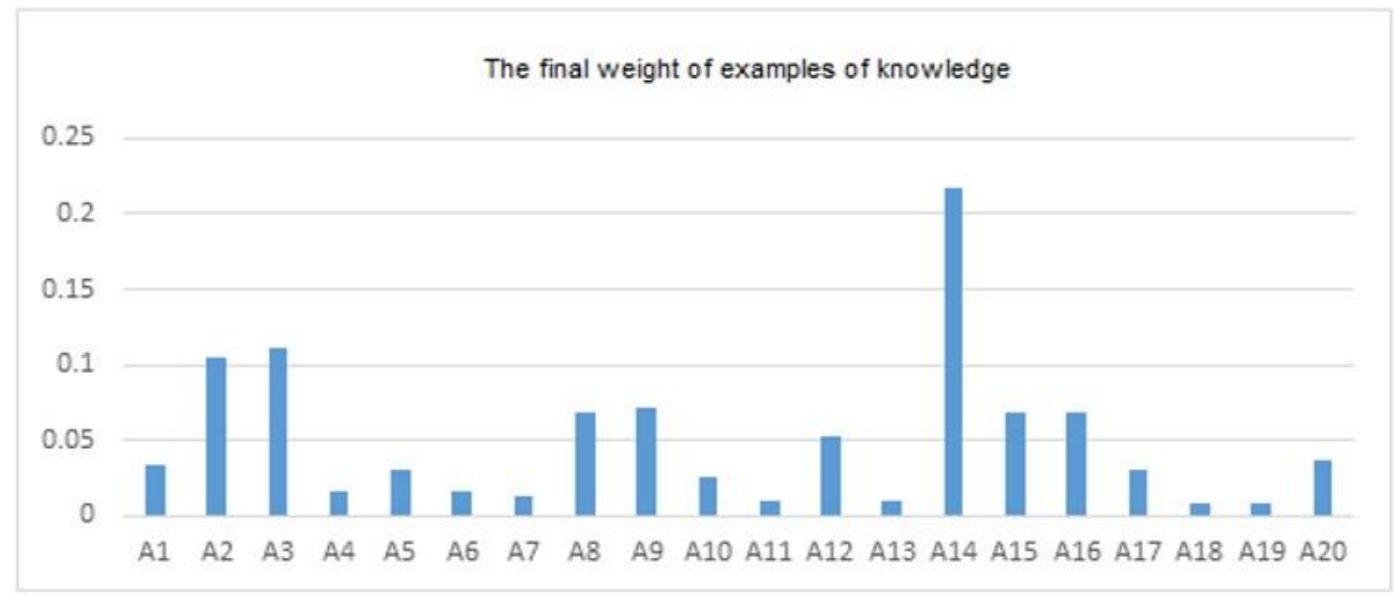

Figure 5. The final weight of criteria

Table 5, after confirming the experts' framework, summarizes the results of the classification of dimensions and examples, some of which are derived from the localization of process models and others from the research literature.

Knowledge from the outside environment, based on its vital Knowledge (Knowledge of stakeholders, competitors, and market knowledge), has the most significant impact on the value of the organization and knowledge about the process (Knowledge of quality management, process, and risk) can create according to its continuous knowledge And improves the process is in the second place. However, as it is clear from the results, knowledge is also practical from other dimensions. 
Table 6. Summary of research results

\begin{tabular}{|c|c|c|c|c|c|}
\hline Rank & $\begin{array}{l}\text { Local } \\
\text { weight }\end{array}$ & total weight & Examples of Knowledge & Weight & $\begin{array}{l}\text { Aspects of } \\
\text { Knowledge }\end{array}$ \\
\hline 12 & 0.0048 & 0.016 & Knowledge of change management & \multirow{6}{*}{0.297} & \multirow{5}{*}{$\begin{array}{l}\text { Knowledge about } \\
\text { the process }\end{array}$} \\
\hline 3 & 0.0297 & 0.1 & Process management knowledge & & \\
\hline 4 & 0.0288 & 0.097 & Quality management knowledge & & \\
\hline 11 & 0.0101 & 0.034 & $\begin{array}{c}\text { Knowledge Management } \\
\text { Knowledge }\end{array}$ & & \\
\hline 7 & 0.0149 & 0.05 & Risk management knowledge & & \\
\hline 8 & 0.0067 & 0.038 & Experience and skills & & \multirow{4}{*}{$\begin{array}{l}\text { Knowledge } \\
\text { during the } \\
\text { process }\end{array}$} \\
\hline 8 & 0.0067 & 0.038 & $\begin{array}{l}\text { The technical and specialized } \\
\text { Knowledge }\end{array}$ & \multirow[t]{3}{*}{0.176} & \\
\hline 6 & 0.0106 & 0.06 & Expert knowledge and mental model & & \\
\hline 9 & 0.007 & 0.04 & Creativity & & \\
\hline 14 & 0.0003 & 0.006 & Input information & \multirow{4}{*}{0.056} & \multirow{4}{*}{$\begin{array}{l}\text { Knowledge input } \\
\text { to the process }\end{array}$} \\
\hline 15 & 0.0002 & 0.004 & Knowledge of documentation & & \\
\hline 10 & 0.002 & 0.036 & Strategic management knowledge & & \\
\hline 13 & 0.0006 & 0.01 & $\begin{array}{l}\text { The knowledge received from the } \\
\text { information system }\end{array}$ & & \\
\hline 1 & 0.0806 & 0.196 & Stakeholder knowledge & \multirow{3}{*}{0.056} & \multirow{3}{*}{$\begin{array}{l}\text { Knowledge from } \\
\text { the outside } \\
\text { environment }\end{array}$} \\
\hline 2 & 0.0621 & 0.151 & $\begin{array}{c}\text { Knowledge of competitors and top } \\
\text { companies }\end{array}$ & & \\
\hline 5 & 0.0263 & 0.0641 & Industry market knowledge & & \\
\hline 13 & 0.0006 & 0.01 & requirements & \multirow{4}{*}{0.056} & \multirow{4}{*}{$\begin{array}{l}\text { Knowledge of the } \\
\text { process output }\end{array}$} \\
\hline 14 & 0.0003 & 0.006 & Output information & & \\
\hline 15 & 0.0002 & 0.004 & Knowledge stored in the system & & \\
\hline 10 & 0.002 & 0.036 & Organisational Learning & & \\
\hline
\end{tabular}

\section{Conclusion}

The analysis results show that the management processes in the process map, including business capability management, risk management, and strategic management, have a significant impact on the knowledge of processes and the organization's value. Given the importance of tacit knowledge during the process that a person involved in the process noted, the importance of developing and implementing staff training or expertise in core processes with high sensitivity is a crucial decision. Due to the nature of the study, organization-based IT services include products with short life due to innovation in payment methods and is also due to the competitive market, the industry, and the efforts of all competitors to increase market share and gain satisfaction and loyalty. The customer can be told that the primary dimension of process knowledge is the environment outside the process. The knowledge of the customer, the knowledge of the competitors, and the importance of the agility of the knowledge providers organization are also essential, so external communications as a support process are essential for creating value. Given the importance of results and ratings, which can be valuable sources of knowledge and understanding of effective processes for policy and planning related to knowledge management, was considered.

It is recommended due to the dynamics of knowledge, and other variables that can affect the value of the influence of system dynamics modeling and simulation can be used to assess the impact of various aspects of process knowledge on the value of systematic and comprehensive as well as Demonstrated the flow of existing knowledge and their cause-and-effect relationships. In future research, examples of knowledge for all significant value chain processes can be identified, and then their impact on the value of the organization can be evaluated. In this way, more accurate 
results can be achieved to plan for sources of knowledge.

\section{References}

Alavi, M., \& Leidner, D. E. (2001). Knowledge management and knowledge management systems: Conceptual foundations and research issues. MIS Quarterly, 25(1), 107-136. https://doi.org/10.2307/3250961

Angeles, J. O. (2015). zonceptualizing a Business Process Knowledge Construct. In Proceedings of the 2015 ACM SIGMIS Conference on Computers and People Research (11-12), ACM. https://doi.org/10.1145/2751957.2755509

Ayoubi, A. (2011). Investigating the relationship between components of organizational knowledge management and creativity. First National Conference on Knowledge Management, Tehran, Oil, Gas, and Petrochemical Information Institute, Management Research and Training Institute.

Bloodgood, J. M., \& Salisbury, W. D. (2001). Understanding the influence of organizational change strategies on information technology and knowledge management strategies. Decision Support Systems, 31(1), 55-69. https://doi.org/10.1016/S0167-9236(00)00119-6

Dang, J., Hedayati, A., Hampel, K., \& Toklu, C. (2008). An ontological knowledge framework for adaptive medical workflow. Journal of Biomedical Informatics, 41(5), 829-836. https://doi.org/10.1016/j.jbi.2008.05.012

Dumas, M., La Rosa, M., Mendling, J., \& Reijers, H. (2013). Fundamental of process management. Springer, Berlin. https://doi.org/10.1007/978-3-642-33143-5

Duran, D. E. S., Builes, J. J., \& Gamboa, A. X. R. (2017, September). A Knowledge Management Model for Improving the Software Test Process. In European Conference on Knowledge Management (pp. 922-929). Academic Conferences International Limited.

Edy, N. (2014). Foresight and System Dynamics in Modelling the Dynamics of Organizational Knowledge.

Entezari, H. (1988). Increasing intellectual capital in the organization and the role of organizational learning. PhD Thesis, University of Tehran, Faculty of Management.

García-Holgado, A., García-Peñalvo, F. J., Hernández-García, Á., \& Llorens-Largo, F. (2015, July). Analysis and improvement of knowledge management processes in organizations using the business process model notation. In Annual Conference of the Global Innovation and Knowledge Academy (pp. 93-101). Springer, Cham. https://doi.org/10.1007/978-3-319-22204-2_9

Jassbi, J., Mohamadnejad, F., \& Nasrollahzadeh, H. (2011). A Fuzzy DEMATEL framework for modeling cause and effect relationships of strategy map. Expert systems with Applications, 38(5), 5967-5973. https://doi.org/10.1016/j.eswa.2010.11.026

Lee, Y. C., Lee, M. L., Yen, T. M., \& Huang, T. H. (2011). Analysis of fuzzy Decision-Making Trial and Evaluation Laboratory on technology acceptance model. Expert Systems with Applications, 23, 1-10. https://doi.org/10.1016/j.eswa.2011.04.088

Mashhadi Hajiali, F., Alvani, M., Kameli, M., \& Memarzadeh, G. (2020). Designing a model of effective knowledge cooperation network in research organizations (Case study: Defense Industry Research Institute). Logistics Thought, 19(74), 87-126.

McIver, D., \& Wang, X-D. "Abby". (2016). "Measuring knowledge in organizations: a knowledge-in-practice approach. Journal of Knowledge Management. https://doi.org/10.1108/JKM-11-2015-0478

Mentzas, G., Halaris, C., \& Kavadias, S. (2001). Modelling business processes with workflow systems: an evaluation of alternative approaches. International Journal of Information Management, 21(2), 123-135. https://doi.org/10.1016/S0268-4012(01)00005-6

Mirshahi, S. (2014). Presenting a model for acquiring knowledge of organizational processes using case-based inference. Tehran Al-Zahra University.

Miskon, S. (2015). Subramanian.p.incorpoating knowledge mapping into km-oriented business reengineering toward better beneficial knowledge. Journal of Information System and Innovation, 54-64.

Nonaka, D. F. (1994). The efficient estimation of vector linear time series model. Biometrika, 63(2), 381-385. https://doi.org/10.1093/biomet/63.2.381

Nonaka, I., \& Von Krogh, G. (2009). Perspective-Tacit Knowledge and knowledge conversion: Controversy and 
advancement in organizational knowledge creation theory. Organization Science, 20(3), 635-652. https://doi.org/10.1287/orsc.1080.0412

Noohpishe, N., \& Taghizadeh, E. (2019). Barriers Influencing Organizations in Developing Country Not Appling Updated Strategic Management Techniques: A Case Study of Iran. Journal of Management and Strategy, 10(5), 25-39. https://doi.org/10.5430/jms.v10n5p25

Ouali, S., Mhiri, M., \& Bouzguenda, L. (2016). A Multidimensional Knowledge Model for Business Process Modeling. International Conference on Knowledge Based and Intelligent Information and Engineering Systems. https://doi.org/10.1016/j.procs.2016.08.247

Qasemian, J., \& Jafarzadeh Kermani, Z. (2019). Study of the status and barriers affecting the use of personal knowledge management by managers (Case study: Organization of Libraries, Museums and Documents Center of Astan Quds Razavi). Journal of Academic Librarianship and Information Research, 53(3), 1-1.

Qureshi, Ali Safarzadeh, J. (2012). The role of business process management in improving performance. Management and Development Quarterly, Shahid Beheshti University of Tehran, No. 7.

Rabiee, Ali. (2011). Knowledge management of processes approaches. Tehran. Tisa.

Roblek, V., Bach, M. P., Meško, M., \& Bertoncelj, A. (2013). The impact of social media to value added in knowledge-based industries. Kybernetes. https://doi.org/10.1108/K-01-2013-0014

Saaty, T. L. (1996). Decision Making with Dependence and Feedback: The Analytic Network Process. RWS Publications, Pittsburgh.

Shim, J. P. (1989). Bibliographical research on the analytic hierarchy process (AHP). Socio-Economic Planning Sciences, 23(3), 161-167. https://doi.org/10.1016/0038-0121(89)90013-X

Starkey, A. (1938). Investigating the Relationship between Information Technology and Knowledge Management of Organizations (Case of North Khorasan Health Insurance Organization). Conference on Management Research and Humanities in Iran, Tehran, Modbar Management Research Institute, University of Tehran.

Taghizadeh, E. (2013). A Multi-Objective Joint Inventory Location Problem with Capacitated Facility Disruption and Penalty Cost: A MOSS Algorithm Approach. In The 6th International Conference of Iranian Operations Research Society.

Taghizadeh, E. (2017). Utilizing artificial neural networks to predict demand for weather-sensitive products at retail stores. arXiv preprint arXiv:1711.08325.

Wu, W. W. (2008). Choosing knowledge management strategies by using a combined ANP and DEMATEL approach. Expert Systems with Applications, 35(3), 828-835. https://doi.org/10.1016/j.eswa.2007.07.025

\section{Copyrights}

Copyright for this article is retained by the author(s), with first publication rights granted to the journal.

This is an open-access article distributed under the terms and conditions of the Creative Commons Attribution license (http://creativecommons.org/licenses/by/4.0/). 